\title{
Writing the Collaborative Process: Measure (Still) for Measure, Shakespeare, and Rape Culture
}

\author{
Cover Page Footnote \\ I want to acknowledge the participants and collaborators in the two project phases to date. In Exeter, they \\ were: Sharanya Murali, Rebecca Benzie Fraser, Samantha Theobald-Roe, Sally Naylor, Nicola Wong, Emily \\ Holyoake, Richard Knox, Harry Kingscott, Ben Gilbert, Evelyn O’Malley, N. Eda Erçin, and Jon Venn. At \\ Nichols, they were: Kristen Tripp Kelley, Kelah Winfield, Lily Thompson, Lizzie Collins, Inti Brittan-Karshud, \\ Myles Hervey, Brian Tank, and Andrew Grimaldi. Thanks are due to Kristen Zaza, who composed music for \\ both iterations, and to Sharanya for writing the poem that closed the Nichols production. I also wish to \\ acknowledge the staff at Exeter's Bike Shed Theatre and faculty and staff at Nichols School, especially Chloe \\ Whipple, Aranya Maritime, and Bill Clough. To personalize this account, I will break with academic \\ convention and refer to participants by their first names.
}


In February 2016, a group of professional performers gathered in an empty shop front in Exeter (UK) to formally begin a devising process with Shakespeare and Middleton's Measure for Measure. ${ }^{1}$ Nearly a year later, in January 2017, a group of high school students in Buffalo, New York (at my alma mater) began a similar process with the same starting point. These groups could not have been more different: in Exeter, they were mostly adult, professional performers, the majority of whom were graduates of the same undergraduate program, and were predominantly white. In contrast, the students in Buffalo were all eighteen-and-under, and diverse by every other imaginable metric. ${ }^{2}$ That these disparate groups undertook very similar processes and arrived at very different results should be no surprise. Recording their separate journeys through the same process, however, necessitates picking apart the structures of power that attach to Shakespeare, education, and performance. ${ }^{3}$ In this article, I attempt to write formally about this process for the first time, with the aim of communicating that the canon can (and should) be challenged, and that it can (and should) be adapted to speak to issues that its authors never imagined, let alone intended. In analyzing the collaborative nature of this process, I hope to destabilize the notion of the singular authorial genius of Shakespeare and refract that authority toward groups that are still marginalized both within Shakespeare studies and Shakespearean performance at professional, amateur, and educational levels.

Measure (Still) for Measure is a practice as research project that aims to use Shakespeare and Middleton's "problem play" to facilitate conversations about rape culture and instigate policy change in educational institution. ${ }^{4}$ It began with a juxtaposition: I was in Austin, Texas on a research trip in the summer of 2015, watching a live-stream of Cheek by Jowl's Russian language Measure for Measure, and simultaneously reading an article about Emma Sulkowicz, who carried her mattress at Columbia University in protest against the administration's failure to expel her rapist. ${ }^{5}$ Isabella's speech in Act 2, Scene 4 stood out at that moment: after being told that she must have sex with Angelo in order to save her brother's life, Isabella asks the audience, "To whom should I complain? Did I tell this / Who would believe me?"6 The line was striking for its seeming contemporaneity: despite the fact that they were written four hundred years ago, it was no leap to imagine Sulkowicz and countless other women speaking the same words in the present. 
Measure (Still) is an experiment grounded in intersectional feminist theory, theater history and historiography, and adaptation studies as well as Shakespeare studies. ${ }^{7}$ It asks its participants to shed any sense of sanctimony they may attach to Shakespeare's works and to play as if the words and characters of Measure for Measure are simply ingredients with which to experiment. (Of course, as we rarely admit, this is closer to the truth of how these texts arrived in the twenty-first century than any narrative of textual or performative fixity.) It asks participants to employ non-linear, "non-hierarchical, practical, and collaborative" modes of storytelling and physical theatre techniques, such as Viewpoints. ${ }^{8}$ The process requires extraordinary vulnerability and bravery from its participants, who are asked to make dramaturgical and performative decisions based on discussions about difficult topics as they apply to the circumstances of the play.

Measure (Still) also relies upon one-off conversations, late-night text messages, and unrelated conference papers as much as it depends upon sustained, deliberate collaboration. It is perhaps a truism to say that all creative activity, including academic outputs, are built on such patchworks of happenstance and dedicated labor. As Baz Kershaw reminds us, "practice as research in the performing arts" always combines "creative doing with reflexive being." I want to highlight this aspect of Measure (Still), however, because in this case, the collaborative process contains a crucial component of the project's impact. ${ }^{10}$ Rape, sexual assault, and sexual harassment are crimes about power: the perpetrator forcibly removes the attacked person's sense of bodily autonomy, of freedom to choose. In this way, the collaborative nature of Measure (Still) for Measure - in which the participants make choices about the adaptation of the script, the casting, and the choreography - can act as an antidote to rape culture. That Shakespeare represents a patriarchal cultural authority is well-established in the field. ${ }^{11}$ Liz Schafer's Ms-Directing Shakespeare points specifically to the effect of Shakespeare-as-patriarchy in terms of opportunities for female directors, who are "[s]tatistically [...] much more likely to direct Shakespeare in the provinces [sic] than in London or at the RSC. ${ }^{12}$ As a result, these women often work without the benefits of a well-funded mainstream theater behind them: "not only are production resources more limited, and access to a pool of performers experienced in playing Shakespeare less attainable, but also [...] the archiving treatment is different." In mentioning archiving, Schafer highlights the politics involved 
in archival practices, which are more robust and thorough at well-funded theatres such as the RSC, where women are rarely invited to direct.

In some small way, then, adapting Measure for Measure and then creating an online archives of the texts produced puts power back into the hands of female practitioners and, in this project, survivors of sexual assault. ${ }^{13}$ Generating opportunities for performers to choose their lines, their physical responses, and their dramaturgies is critical to the success of the project; foregrounding these choices through a pre-show introduction and a post-show Q\&A helps audiences engage with the material and appreciate the collaborative process. As Schafer reminds us, there is a politics in acknowledging the many acts of informed and empowered choice that have made Measure (Still) what it is.

It is also crucial to note that despite its engagement with psychologically traumatic events such as sexual assault, Measure (Still) has no aspirations to cognitive research impact - that is, unlike projects such as Nicola Shaugnessy and Melissa Trimingham's Imagining Autism, Measure (Still) can make no claim to the scientific expertise necessary to generate measurable psychological changes in individuals. ${ }^{14}$ While such work is obviously valuable and important, this project aims at cultural, policy- and curriculum-based change. In this way, it is more in the mode of practice as research that celebrates the "[n]umerous instabilities in the diversity and ephemerality of performing arts practices" that nonetheless "pose particular challenges to ideas of fixed, measurable and recordable 'knowledge." 15 Cultural changes take time; institutional change at the level of policy and curriculum can feel glacial. We may feel frustrated by the pace and ephemerality of these outcomes, but the work must be done and documented nonetheless.

Documenting Measure (Still) therefore presents the challenge of nailing down collaborative, often spontaneous or experimental decision-making in the rehearsal room. This problem has not gone unnoticed in academic writing; indeed, since 2010 the Theatre and Performance Research Association (TaPRA) has dedicated a working group to the subject of Documenting Performance. The title of Gay McAuley's 2012 monograph Not Magic But Work places the issue front and center, emphasizing the creative, intellectual, and physical "work" undertaken by the constellation of people involved in a rehearsal process. ${ }^{16}$ Like McAuley, I am "vitally interested in the complex nature of collective 
creativity," but in the case of this particular project, I position myself as an insider, rather than an outsider/ethnographer. ${ }^{17}$ This positionality is not without its challenges in terms of writing about the project; as McAuley notes, it is difficult for the ethnographer to become a "quasi-insider" because the responsibilities of a creative team member leave little time for the kind of note-taking and writing up that must occur on a daily basis in ethnographic fieldwork. ${ }^{18}$ In my case, as the project lead and main facilitator, I rehearsed part-time alongside many other responsibilities, including at least one other part-time job and unpaid scholarly labor.

McAuley's work underlines another issue in documenting Measure (Still): like most accounts of rehearsal and development processes, her work focuses on a scripted play. Her list of "directors, actors, and playwrights" as the primary writers of process suggests a history of rehearsal writing that is steeped in drama-in the sense of scripts and plays - rather than performance. But who is the author of Measure (Still) for Measure? Its shape, its dramaturgy, plot, and characterization in the context of the adaptation - or, even, in the context of any individual iteration of the adaptation - is determined by the participants involved in the creative process. Measure (Still) as performed at Nichols School in May 2017 bore little resemblance to the seventeenthcentury play: it occupied a mere thirty minutes of playing time, all but cut the character of the Duke, and featured four Isabellas.

Within Shakespeare studies, writing about performance-as-process has recently come into vogue. Barbara Hodgdon centers rehearsal in the opening of her latest book, Shakespeare, Performance, and the Archive, noting that "[p]erformance 'survive[s] as a cluster of narratives' - everyone in that rehearsal room [has] a different story to tell."19 Her application of Derrida's Archive Fever is particularly appropriate for this project:

if one finds nothing but white space, that absence is not nothing but rather the space left by what has disappeared: the very emptiness constitutes a sign of how, in performance, the space was once filled and animated. ${ }^{20}$

In this case, the "space left by what has disappeared" focuses the work done by Measure (Still) to shift authority away from Shakespeare and onto the performers who enter the project. Measure (Still) aims at its own disappearance: its methods require that each new iteration reflects the present group of participants and the concerns and priorities most 
relevant to them. While trends and tendencies across iterations may emerge, new participants are not asked to engage with previous iterations in any extended or prescriptive way. There are common starting points (centering Isabella, for example), but the context-specific process will always lead to different results. Borrowing from Kershaw, the process is "multi-modal and has the qualities of a moveable feast: always already the "same' project but forever differently displayed." ${ }^{21}$ Difference between iterations is one of the project goals: it asks participants to use the base text to address issues that are specific and important to their community. As such, it precludes the level of "reperformance" experienced by Hodgdon in the RSC's archives. ${ }^{22}$

Missing from most accounts of performance-as-process with Shakespeare Studies is a sense of performance as detached from a script or promptbook. There are, however, a couple of examples of writing that analyzes non-linear modes of performance arising from playtexts - some of which have been published in this journal. Shanahan et al., for example, make use of María Irene Fornés's Fefu and Her Friends to probe the limits of performative gender theory and embodied knowledge; the second part of Fornés's play is fractured, fragmented, and non-linear, which, the writers argue, allows for an explicitly "feminist experiment in alternative forms of dramatic storytelling." ${ }^{23}$ Elsewhere, Dani Bedau and D.J. Hopkins enumerate a performance process undertaken with their students in their university library: using Shakespeare as inspiration, the project asks students to think about how they might "get an audience to experience Shakespeare as both "to be read' and 'to be performed." 24 Both of these projects provide a framework for thinking about embodied knowledge in relation to performance that happens outside of typical theatrical settings.

W.B. Worthen, in framing his attempt to define the existing but unacknowledged field of Shakespeare Performance Studies, imagines an approach that results in "a more productive encounter, a more productive study of performance through Shakespeare" than existing methodologies that "[tend] to inflect 'Shakespeare performance' as finally about the Shakespearean text, as merely another interlocutor with Shakespeare's literary designs." ${ }^{25}$ Resisting this kind of relationship to Shakespeare drives Measure (Still), which uses Shakespeare as a lens through which to talk about and process issues that were probably far from his consciousness. The function of Shakespeare as a symbol for 
patriarchy and, in many ways, the ultimate white, male, cis-het, able-bodied authority, is one that the project seeks to undermine.

At this point, it is relevant to link the cultural authority wielded by Shakespeare and the broad issue of rape culture in the twenty-first-century Anglophone world. When the stories that we prioritize culturally are also those that elevate the voices of toxic masculinity (e.g., the Duke in Measure for Measure) as protagonists, we continue to marginalize those whose stories have historically been sidelined. Since Shakespeare is still a seat of cultural authority whose plays also participate in rape culture, it makes sense to address the two issues together. ${ }^{26}$ In other words, chipping away at Shakespeare's well-established cultural authority can also be a strategy for dismantling rape culture. ${ }^{27}$

\section{The Measure (Still) Process}

Measure (Still) continues to evolve, and the process changes with each new group of participants, both in response to feedback and the rapidly changing socio-political landscape of the early twenty-first century. The initial Exeter phase of Measure (Still) was designed more to test a process than to produce a measurable outcome. In applying and adjusting this process at Nichols a year later, our goal was to generate conversations about rape culture both through the Q\&As after the performances and through the cast's interactions outside of rehearsal and performance with other students, teachers, and administrators. In this section, I enumerate the shape of the processes to date, with the intention of showing some of what is possible when creating work which goes against the grain of Shakespeare's cultural authority.

As I note above, I hatched the idea for Measure (Still) in the spring of 2015, in Austin, Texas. Upon my return to England for the final year of my doctoral program, I recruited professional performers and students in Exeter for a series of informal, experimental workshops on the project's themes that ran from September of 2015 through January of 2016. Through these workshops, we experimented with exercise formats that generated non-linear and abstract performance modes arising from engagement with Viewpoints. ${ }^{28}$ This framework emphasizes "non-hierarchical art," which is enormously important to collaborative creation. ${ }^{29}$ For example, we took select 
scenes from Measure for Measure and imagined that all of the text was "available" to be used by any performer, at any point in the scene. Working through an extended improvisational exercise using Viewpoints-sometimes referred to as a "jam"performers could draw upon any words, phrases, lines or speeches from the scene that felt appropriate or relevant, either in isolation or in response to another performer. Repetition, paraphrasing, and permutation were encouraged: participants were told not to worry about word-perfect memory and to rely instead on their sense of the line and its deployment in the unfolding improvisation. This process of improvisational experimentation resulted in some exciting discoveries: in one improvisation, the women all played Isabella, and the men all played Claudio; the text was derived from Act 3, Scene 1, in which Isabella tells Claudio that he must die if she does not submit to Angelo. Claudio's line "Why give you me this shame?" was picked up by the women playing Isabella and tossed around the room in different permutations for much of the exercise. ${ }^{30}$ In particular, the words "why" and "shame" were repeated incessantly, with varying inflections and applications, throughout the exercise.

These experiments with form resulted in reproducible exercises that unlocked possibilities for non-linear adaptation and shook free much of the lingering rigidity in our approach to "Shakespeare's text." One of the key discoveries during this period was the extraordinary power of casting multiple Isabellas, and Angeloes. The number of performers working on one side or the other communicated shifts in control. At the same time, this approach deflected many of the common excuses made in cases of sexual assault: that the perpetrator is just a "bad guy" or an outlier, and that the survivor was somehow "asking for it" through their dress or state of intoxication. Multiplying the faces and bodies associated with each character interrupted those narratives by denying them a stable foothold.

During this time, I also worked with Sharanya Murali and Rebecca Benzie Fraser-who served as dramaturgical consultants throughout the project - to develop an adapted text of Shakespeare and Middleton's play, based on our studio experimentations. Sharanya and Rebecca were present for and participated in a number of the practical sessions, and therefore worked on the script with first-hand knowledge of how it might be deployed in performance. 
To begin, we cut any scenes that did not feature Isabella. We also changed Claudio's gender so that Isabella had a sister, Claudia, instead; her crime was still "fornication," but the same-sex nature of the relationship (sans pregnancy) inflected her persecution by Angelo. In addition, this change created space for a meaningful relationship between Isabella and Juliet, Claudio/a's fiancée; early in the play, Isabella describes Juliet as her "cousin[...] /Adoptedly, as schoolmates change their names / By vain though apt affection." ${ }^{31}$ We found it strange that this seeming affection for Juliet did not manifest in any advocacy on her behalf, or any acknowledgment of her plight from Isabella later in the play. Expanding Juliet's role by re-assigning some of Claudia's lines offered opportunities to represent different kinds of womanhood and relationships between women, including explorations of solidarity and failure thereof:

JULIET: Oh, heavens, it cannot be.

ISABELLA: Yes, he would give't thee, from this rank offense, So to offend him still. This night's the time That I should do what I abhor to name, Or else thou diest tomorrow.

JULIET: Thou shalt not do't.

CLAUDIA: Death is a fearful thing. ${ }^{32}$

The manipulation of this scene allowed us to create two responses to Isabella's dilemma: a response in solidarity — Juliet's "Thou shalt not do it"- juxtaposed against Claudia's more self-centered response: "Death is a fearful thing." This relatively small change proved a powerful intervention into Measure for Measure's masculine narrative: the women involved in our process took ownership of a marginalized relationship from Shakespeare and Middleton's play and extended it.

Among other interventions at this stage-which we discussed, developed, and tested in the studio - were the removal of Isabella's religious convictions, which seemed like a crutch used by Shakespeare to soften her refusal of Angelo, and the removal of the brothel plot with Mistress Overdone. This latter cut was hotly debated between Sharanya, Rebecca, the actors, and myself; we felt uneasy about eliminating a sex worker character and her story. Ultimately, however, we decided that focusing on Isabella's story would give us greater clarity in a short, abstract, and non-linear piece of performance. 
This initial process of studio experimentation alongside textual adaptation led us to a few solid scenes: versions of Act 2, Scene 2; Act 2, Scene 4; and Act 3, Scene 1. The second half of the play proved more difficult. A number of questions arose: what should be done with Mariana, who functions mostly as a plot device by facilitating the "bed trick" in Act 4? How to get around the Duke's total dominance of Act 5? Should Mistress Overdone be cut or retained? What about the complicated "head trick" that saves Claudio/a's life? We hoped to address these questions, with help from playwright Emily Holyoake, in our funded rehearsal and development (R\&D) week with the Bike Shed Theatre.

The week began with exercises in Viewpoints and contact improvisation, which were already familiar to all the performers. Our contract with the Bike Shed required a public showcase at the end of the five-day residency. With such limited time to work and rehearse, the participants' familiarity with physical theatre techniques and with each other was paramount to the success of the experimentation. We produced twelve minutes of material, some of which took the form of semi-structured improvisations, using original music delivered electronically and tweaked throughout the week in response to prompts from the performers by Toronto-based actor and composer Kristen Zaza. Intensive work on the scenes that we chose to perform for our showcase was punctuated by time taken to discuss the often difficult issues that arose; these conversations grounded our devising, provided the opportunity for real-time feedback on the process, and helped all of us both digest and debrief the work.

Our intention had been to work out the problems that persisted in the second half of the adapted script. Once we were in the space, however, we found ourselves drawn to further experimentation with the scenes that already "worked" on the page; their solidified structure left us feeling freer in our manipulations of and experimentations around the text. In the end, our showcase made use of the three complete scenes $(2.2,2.4$, and 3.1) but did not manage to push the latter half of the play forward.

In the months that followed, I continued working with Sharanya, Rebecca, and movement consultant Harry Kingscott to further develop an adaptation of Acts 3, 4, and 5. Ultimately, we decided to test some radical cuts: the subplot, Mariana and the bed trick, the head trick, and most of the Duke's role. A conversation with Kevin Costa, 
Director of Innovation and Learning at the McDonogh School in Baltimore, sparked an idea for the final scene: if the goal was to center Isabella and her experience, then why not cut everything but her lines? This suggestion created a powerful monologue for Isabella that anchored the final act and effectively unseated the Duke as the puppet master of the play.

\section{Nichols Residency}

Before diving into the process as it played out at Nichols, it is important to contextualize that community as a project participant and stakeholder. Nichols is an elite, independent private school that has been working hard-especially over the past ten years - to diversify its student body. It was a school for boys until 1973 and celebrated its 125th birthday in 2017. A brief perusal of the specially-produced anniversary issue of Toaxnoes - the informational magazine named for the school's Greek motto, translated as "truth" - demonstrates the staggering racial homogeneity of Nichols" alumni. To work with a group of seven seniors that included four students of color would have been numerically impossible until very recently; that the Measure (Still) group was also majority female, included queer and disabled students, and mostly held jobs outside of school, also speaks to the hard work being done to make Nichols a more inclusive space.

At the request of Arts Department Chair and co-facilitator Kristen Tripp Kelley, I worked with Sharanya, Rebecca, and Harry to complete a "Nichols Draft" of the adapted script, based on the Bike Shed process and incorporating the cuts to the latter half of the play outlined above. This, we hoped, would serve as an inspiration and a starting point for the students involved in the Nichols phase of the project, who were not used to thinking about Shakespeare in adaptation - or even Shakespeare as adaptable. Providing an example of what the script might look like would, we hoped, open the door to the students' own dramaturgical experimentations. In presenting the Nichols Draft to the students as a starting point for their process, Kristen and I also included the following rules:

1. You can't add something to Shakespeare and Middleton's Measure for Measure that is not by a cast member, a woman, and/or a person of color.

2. You can cut as much of Shakespeare and Middleton's play as you want. 
3. The rehearsal room is a safe and intersectional space. ${ }^{33}$

These rules invited students to add texts of various kinds that they felt connected to while prioritizing the marginalized voices that the project sought to elevate. In practice, our "safe and intersectional space" manifested in students' willingness and ability to discuss the sensitive issues raised by the play in the confidence that their classmates would engage in respectful (but still passionate) ways. The relatively horizontal power structure required by the Viewpoints system in particular started from day one, when the students and I sat down together to map out our plan for the semester. This collaborative planning process made it clear that everyone's voice was valuable and worth hearing in our process.

In this spirit, students also suggested a number of "secondary" texts for incorporation into the performance. Excerpts from Beyoncé's Lemonade and the letter read in court by the survivor of Brock Turner's rape at Stanford, quotes from Margaret Atwood, and music by Björk, Pat Benatar, and FKA Twigs were all added to the script as interventions that personalized and disrupted the Shakespearean text. ${ }^{34}$ For example, after performer Kelah Winfield as Isabella heard Angelo's ultimatum, we moved from Shakespeare's text to a section of the letter read aloud at the 2016 Stanford rape trial. The prompt script transitions here to using the students' first names to identify line assignments, as they all took on the personae of the police officers who took the Stanford survivor's statement. Kelah, in turn, transitioned from her character, Isabella, to a version of herself; or, more accurately, found a middle ground between herself and Isabella for this sequence:

[Exit ANGELO]

ISABELLA: To whom should I complain? Did I tell this -

ALL (men and women): - who would believe me?

MYLES: How old are you?

BRIAN: How much do you weigh?

LILY: What did you eat that day?

INTI: Well what did you have for dinner? 
LIZZIE: Did you drink with dinner?

ANDREW: No, not even water?

MYLES: When did you drink?

BRIAN: How much did you drink?

LILY: What container did you drink out of?

INTI: Who gave you the drink?

LIZZIE: How much do you usually drink?

ANDREW: At what time?

MYLES: But where, exactly?

BRIAN: What were you wearing?

LILY: Why were you going there?

INTI: What'd you do when you got there?

LIZZIE: Are you sure you did that?

ANDREW: But what time did you do that?

MYLES: What does this text mean?

BRIAN: Who were you texting?

LILY: Are you serious with your boyfriend?

INTI: Are you sexually active with him?

LIZZIE: When did you start dating?

ANDREW: Would you ever cheat?

MYLES: Do you have a history of cheating?

BRIAN: Do you remember any more from that night?

LILY: No?

INTI: Okay.

ALL: We'll let him fill it in. 


\section{[ALL repeat questions ad lib, overlapping and getting louder and faster} until...]

\section{KELAH: STOP! [ALL freeze] Who will believe me? $?^{35}$}

In tearing the audience out of language from the seventeenth century and dropping them into a text that, at the time of performance, was barely a year old, the ensemble articulated an argument for Measure for Measure's relevance in the present. In addition, by using a contemporary survivor's own report of her treatment by police following an assault, they intervened in the narrative of Shakespeare's authority over stories such as Isabella's and addressed the on-going, systemic problem of authority figures who do not intervene appropriately in such cases.

The combination of these rules and the sample adapted script worked better than we could have hoped as catalysts for the Nichols students' approach to adaptation. Our process was constrained by several factors, however. Most rehearsals took place during the school day, during the students' Advanced Acting class period. Classes at Nichols run for forty-seven minutes; once per seven-day cycle, we had a "double" class period, and spring break fell less than two weeks before our performances. School assemblies and other events sometimes truncated our already squeezed meetings. My own work schedule did not allow me to attend rehearsals that took place in the morning for a significant portion of the process. Two performers acquired injuries from sports that restricted their movement, and one had an emergency surgery halfway through the process. Finally, "Senioritis" and its attendant disengagement sometimes affected the otherwise very motivated and dedicated cast.

Importantly, however, students were also aware-particularly at the beginning and end of the process - that their work was being assessed for a grade. Here, Kristen's established rapport with her students, Nichols' dialogic approach to pedagogy as an institution, and the cast's relatively secure position as graduating seniors - many of whom had been accepted to colleges through Early Decision or Early Action before our process began-eased what may otherwise have been a serious challenge to our aim of creating a non-hierarchical rehearsal and performance space. ${ }^{36}$ Future iterations of this project in other settings may have to grapple with this issue more explicitly. 
Over the course of four months, Kristen, the students, and I generated about thirty minutes of material. Our slower pace of creation compared to the Exeter process reflects both the greater scope of the work - the whole play as opposed to a few scenes - and the relative experience and skill level of the performers. The students undertook significant dramaturgical work in the first half of our process, working both from the initial Nichols Draft script and from a full copy of the play; a Skype session with Sharanya and Rebecca helped students clarify their ideas. Some conversations were intense: once the group had decided to retain the Draft's cut of the bed trick, Lily felt very strongly that Isabella should sleep with Angelo if it would save her brother's life. She argued intelligently and passionately for this outcome even when the rest of the students disagreed with her; ultimately, the majority won, and our Isabella refused Angelo at the cost of Claudio's life. In this iteration, Claudio actually died because there was no Mariana to save him.

Lily spoke in post-show Q\&A sessions about how the experience of arguing against the group had inflected her performance as Isabella, particularly in Scene 4 of the Nichols Prompt Script, when she confronted Brian's Claudio and Inti's Juliet with Angelo's ultimatum. When the group was asked, on the night of the first performance, about how they came to collective decisions about the script, everyone immediately looked to Lily, who articulated the battle she fought for a different version of the story. Ultimately, she conceded, the group's decision was dramaturgically effective; she stood by her determination that she would do anything to protect her own brother in "real life."

Such connections between Measure (Still) and "real life" situations were more than theoretical: just weeks after the students performed their version of the piece, Nichols announced an investigation into allegations of sexual misconduct against some of its former teachers. ${ }^{37}$ While I have no definitive evidence that Measure (Still)'s presence at Nichols motivated or directly influenced the decision to proceed with the investigation, I will note that the headmaster, senior members of the school's administration, and members of the Board were all present for either dress rehearsals or performances and engaged in Q\&A with the students in May 2017.

There were happy accidents, too. Kristen and I only realized on opening night, when Myles Hervey's mother was in the audience, that we had cast him in such a way that he journeyed through a stereotypical performance of a black man into a more 
redemptive and positive role. Watching Mrs. Hervey's reaction to Myles' first appearance as Angelo was absolutely heartbreaking: she saw her son represented as misogynist, abusive, and unfeeling. Myles was the first performer to play Angelo, compounding the sense that he had been cast stereotypically. His next appearance, however, was as the Duke-who, in this version of the piece, is the only man who listens to, believes, and supports Isabella. In this final scene, the Duke entered with Angelo (then played by Brian Tank), praising him for his leadership: “And we hear / Such goodness of your justice, that our soul / Cannot but yield forth public thanks_ "38 The four female performers, led by Kelah and Lizzie, cut him off:

Justice, O royal duke? [...]

O worthy prince, dishonour not your eye

By throwing it on any other object

Till you have heard me in my true complaint

And given me justice, justice, justice, justice! ${ }^{39}$

Lizzie delivered this speech alone until she reached the final line, where Kelah, Lily, and Inti jumped in; a new voice joined with each repetition of "justice" until all four women were speaking in unison. This choral style of speech was deployed at several points in the last scene to create a sense of solidarity between the four women playing Isabella and to underline one of the project's key take-home messages: any of us could be Isabella. When the women had finished their exhortation of Angelo, they moved to leave the space, led by Kelah's line: "I, thus wronged, hence unbelieved go." ${ }^{40}$ Myles - as the Duke - stopped them by calling out, "Isabel! I have a motion much imports your good, / If you'll a willing ear incline?" This line comes directly from Act 5 of Measure for Measure, but in Shakespeare and Middleton's version, it leads to a proposal of marriage and Isabella's silence. ${ }^{41}$ Instead, we took things in a different direction: after receiving Isabella's (Kelah's) consent to voice his "motion," the Duke called out, "Provost! [Enter PROVOST] Take him away." ${ }^{42}$ Angelo was led away, loudly protesting the Duke's capitulation to "these girls, these liars!" 43

This ending both rehabilitates the Duke-especially with Myles in the role, which affords an opportunity to dismantle stereotypical representations of black men-and creates a kind of feminist fantasy: the survivor, Isabella, is believed; the attacker, Angelo, is arrested; the person in power, the Duke, works for rather than against justice. It also 
upends the existing power structures of the justice system in America: Kelah and Myles, as black actors, watched white actor Brian (as Angelo) justly arrested and taken away.

The transition out of the final scene and into the epilogic choral poem, however, undercut any sense of a pat happy ending; a moment of victory was complicated by the knowledge that this Angelo (and all the Angelos he stands for) had yet to be prosecuted and/or convicted. The inclusion of text from the 2016 Stanford rape trial earlier in the performance underscored an uncomfortable truth: even if an Angelo is later convicted-a statistical unlikelihood in the United States - he may not receive much in the way of punishment. The closing poem served another purpose, however: we were reluctant, as a group, to close the play with the Duke and Angelo's words. In Shakespeare and Middleton's play, the Duke closes the dialogue with a marriage proposal to Isabella, who does not give a verbal response. The lacuna of Isabella's answer to the Duke haunts many readings of Measure for Measure. Asked to imagine a response, Sharanya wrote a choral poem for Isabella. Led by Kelah, the four women in the Nichols production closed the play repeating Sharanya's powerful lines:

We say our names, our truth to seal your plight

Your lies we return to you, like glass to the kite. ${ }^{44}$

This ending represented many of the project's goals: words for women, written by women, supplanting the authority of Shakespeare and creating a different kind of narrative.

\section{Practice, Theory, Politics, and the Personal}

I would argue that the personal is not only political but is also essential to the academic: as Arthur L. Little, Jr. emphasized in his address to the 2017 Annual Meeting of the Shakespeare Association of America (SAA), the pretense of detachment - the recourse to the impersonal, "objective" scholarly position-is a signifier of privilege. No such objectivity actually exists; rather, it is claimed by those who seek to retain their influence over and above scholars who do not fit the white, male, cis-het mold. Little frames his argument specifically in terms of race, but such distinctions are also applied as gatekeeping devices across many identity markers: 
[The] tacit and tactical deployment of an impersonal-meaning authoritatively personal-white privilege becomes a shorthanded way of claiming a phenomenological or osmotic fit between Shakespeare and the white scholar, even as so many of these same white scholars are confident in the racelessness not just of Shakespeare but [of] their own scholarly practices. ${ }^{45}$

In clarifying the "impersonal" as the "authoritatively personal," Little highlights a key problem in the claim to objectivity or academic distance that characterizes certain kinds of scholarly endeavors. Those scholars whose privilege protects them from attention paid to their gender, race, ability, or class, for example, are those whose personal interests experiences tend to be framed as authoritative and therefore objective. Their voices are assumed to speak universally, whereas black and/or female and/or disabled voices are assumed to speak only for the identity group(s) to which they are seen to belong.

Through their work on Measure (Still) at Nichols, students from a variety of identity groups traditionally underrepresented in Shakespearean performance and Shakespeare studies intervened in one of the most problematic plays of Shakespeare's canon. They absorbed and understood the story that Shakespeare and Middleton told four hundred years ago, and then pushed back against that narrative in order to tell the same story differently. They displaced the Duke as protagonist and elevated the voices of diverse women - through the casting of multiple Isabellas-in his place. These interventions are personal as much as cultural and political. Institutional and cultural change is slow, but this is how it starts.

${ }^{1}$ It is now generally accepted in the Shakespeare community that Measure for Measure was edited and revised by Thomas Middleton sometime between its first performances and its publication in the First Folio (1623). For a fuller explanation of the rationale behind this dual attribution, see John Jowett and Gary Taylor, Shakespeare Reshaped, 1606-1623 (Oxford: OUP, 1993), especially pp. 107-236. See also Jowett (ed.), "Measure for Measure: A Genetic Text" in The Collected Works of Thomas Middleton, ed. Taylor and John Lavagnino (Oxford: Clarendon, 2007), 1542-85.

${ }^{2}$ In order to personalize this account, I break with academic convention and use participants' first names throughout. Names have not been changed; permission was obtained from all participants to use their names and work in this article and on the project website. I address the importance of the personal in the Measure (Still) for Measure project in the final section of this article. 
${ }^{3}$ For additional reading on Shakespeare, authority, and culture, see, e.g.: Michael Bristol, Big-Time Shakespeare (London: Routledge, 1996); M.J. Kidnie, Shakespeare and the Problem of Adaptation (London: Routledge, 2008); Ania Loomba, Shakespeare, Race, and Colonialism (Oxford: OUP, 2002); W.B. Worthen, Shakespeare and the Authority of Performance (Cambridge: CUP, 1997).

${ }^{4}$ The term "problem plays" in Shakespeare Studies refers to a group of plays - usually, Troilus and Cressida, All's Well That Ends Well, and Measure for Measure - that do not fall neatly into the categories of tragedy and comedy. Some critics also include plays like The Winter's Tale, Timon of Athens, and The Merchant of Venice. The terms was coined in 1896 by F.S. Boas in Shakespeare and His Predecessors.

${ }^{5}$ Roberta Smith, "In a Mattress, a Lever for Art and Political Protest," New York Times, Sept. 21, 2014, https://www.nytimes.com/2014/09/22/arts/design/in-a-mattress-afulcrum-of-art-and-political-protest.html.

${ }^{6}$ William Shakespeare, Measure for Measure, ed. Stephen Greenblatt et al (London: Norton, 1997), 2.4.171-2.

${ }^{7}$ The work of Ania Loomba, Ayanna Thompson, Lisa Jardine, Sara Ahmed, Roxane Gay, Chimamanda Ngozi Adichie and Ijeoma Oluo has been foundational for this project. Within theatre history and historiography, I am indebted to the work of Kate Newey, Jane Milling, Tom Postlewait, Charlotte Canning, Bruce McConachie, Martin White, and Peter Thomson. From adaptation studies, Linda Hutcheon, Kara Reilly and Vicky Angelaki's work has been instructive.

${ }^{8}$ Anne Bogart and Tina Landau. The Viewpoints Book: A Practical Guide to Viewpoints and Composition. New York: Theatre Communications Group, 2005, 15. Viewpoints is a system originally developed by Mary Overlie as an improvisational tool for dancers; the system was adapted and expanded by Bogart, Landau, and the Siti Company.

${ }^{9}$ Baz Kershaw et al., "Practice as Research: Transdisciplinary Innovation in Action" in Research Methods in Theatre and Performance, ed. Baz Kershaw and Helen Nicholson (Edinburgh: Edinburgh UP, 2011), 64.

${ }^{10}$ See Deirdre Heddon and Jane Milling, Devising Performance: A Critical History (Basingstoke: Palgrave Macmillan, 2005).

${ }^{11}$ See, for example, Kathleen McLuskie, "The Patriarchal Bard: Feminist Criticism and Shakespeare: King Lear and Measure for Measure." in Political Shakespeares: Essays in Cultural Materialism, ed. Jonathan Dollimore and Alan Sinfield. $2^{\text {nd }}$ edition. (Ithaca: Cornell University Press, 1994), 88-108, and Dympna Callaghan (ed.). A Feminist Companion to Shakespeare. $2^{\text {nd }}$ edition. (Malden, MA: Wiley Blackwell, 2016).

12 Elizabeth Schafer. Ms-Directing Shakespeare: Women Directing Shakespeare. (New York: St. Martin's Press, 2000), 3.

${ }^{13}$ All texts created through the Measure (Still) for Measure project can be viewed on the project's website, http://measurestill.wordpress.com.

${ }^{14}$ Shaun May, Rethinking Practice as Research and the Cognitive Turn (London: Palgrave, 2015), 9.

${ }^{15}$ Robin Nelson, Practice as Research in the Arts: Principles, Protocols, Pedagogies, Resistances (London: Palgrave, 2013), 15. 
${ }^{16}$ Gay McAuley, Not Magic But Work: An Ethnographic Account of a Rehearsal Process (Manchester: Manchester University Press, 2012), 29.

${ }^{17}$ McAuley, Not Magic, 28.

${ }_{18}$ McAuley, Not Magic, 8-9.

${ }^{19}$ Barbara Hodgdon, Shakespeare, Performance, and the Archive (Abingdon: Routledge, 2016), 2.

${ }^{20}$ Hodgdon, Shakespeare, 13. See also Peggy Phelan. Unmarked: The Politics of Performance. (London: Routledge, 1993).

${ }^{21}$ Kerhsaw, "Practice as Research," 66.

${ }^{22}$ Hodgdon, Shakespeare, 10. See also Rob Conkie, Writing Performative Shakespeares: New Forms of Performance Criticism (Cambridge: CUP, 2016).

${ }^{23}$ Ann M. Shanahan et al., "Performance: An Approach to Strengthening Interdisciplinarity in Women's Studies and Gender Studies," PARtake 1.1 (2016): Article 4, http://scholar.colorado.edu/partake/vol1/iss1/4. Sarah Ruhl's short essay "On Andy Goldsworthy, theatrical structure, and the male orgasm" is perhaps the most famous iteration of the idea that the traditional Aristotelian dramatic structure mirrors the pattern of male arousal and orgasm: "I remember once hearing a young male student describe the structure of his play. He said, 'Well, first it starts out, then it speeds up, and it's going and it's going, and then bam, it's over.' And I thought, Do we think the arc is a natural structure because of the structure of the male orgasm?" (8). Ruhl elaborates on this point in an interview with P. Carl for Howlround in 2014: "I really hesitate at describing storytelling in such a way because it leads to these weird essentialist assumptions, like we're doomed to write the way we orgasm, or we all orgasm the same according to our gender. I do think there's something in the culture that has held up this arc as the only and the normal story structure, and this kind of moment-to-moment experience of unfolding is newer territory."

${ }^{24}$ Dani Berdau and D.J. Hopkins, “The Shakespeare Laboratory: Intercepting 'Authority' through Research, Pedagogy, and Performance," Theatre Topics 23.2 (2013): 150.

${ }^{25}$ W.B. Worthen, Shakespeare Performance Studies (Cambridge: CUP, 2014), 3. Emphasis original.

${ }^{26}$ See, e.g., Pascale Aebischer, Shakespeare's Violated Bodies: Stage and Screen Performance (Cambridge: CUP, 2004); Barbara Hodgdon, "Who is performing 'in' these text(s)? or, Shrew-ing around" in In Arden: Editing Shakespeare, ed. Ann Thompson and Gordon McMullan (London: Thomson, 2003), 95-108; Lisa Jardine, Still Harping on Daughters (New York: Columbia UP, 1989); Carol Neely, Distracted Subjects: Madness and Gender in Shakespeare and Early Modern Culture (Ithaca: Cornell UP, 2004); Ayanna Thompson, Passing Strange: Shakespeare, Race, and Contemporary America (Oxford: OUP, 2013).

${ }^{27}$ For detailed studies of Shakespeare's cultural authority and its effects in the United States and around the world, see (e.g.) Michael Bristol, Big-Time Shakespeare; Ania Loomba, Shakespeare, Race, and Colonialism; Susan Bennett, Performing Nostalgia; and Ayanna Thompson, Passing Strange. 
28 This work was based on my own training through the University of Toronto

(Mississauga) and Sheridan College's Theatre and Drama Studies (TDS) program and University of Exeter as well as Bogart and Landau's The Viewpoints Book.

${ }^{29}$ Bogart and Landau, The Viewpoints Book, 4.

${ }^{30}$ Measure (Still) for Measure, (unpublished: Bike Shed Script, 2016), 6.

${ }^{31}$ Shakespeare, Measure for Measure, 3.1.46-7.

${ }^{32}$ Measure (Still), (Bike Shed), 6-7.

${ }^{33}$ Measure (Still) for Measure (unpublished: Nichols Prompt Script, 2017), 1.

${ }^{34}$ Michael E. Miller, "All-American Swimmer Found Guilty of Sexually Assaulting Unconscious Woman on Stanford Campus," Washington Post, March 31, 2016, https://www.washingtonpost.com/news/morning-mix/wp/2016/03/31/all-americanswimmer-found-guilty-of-sexually-assaulting-unconscious-woman-on-stanfordcampus/?utm_term=.38a40ead1d13.

${ }^{35}$ Measure (Still) (Nichols Prompt), 11-13.

${ }^{36}$ At Nichols, students were awarded grades out of twenty in five broad categories, for a total possible score of 100. Categories included the performances themselves, participation in rehearsal and discussions (including video journals completed at the end of the process), script work (including the dramaturgical process of adapting and cutting the text of Measure for Measure), technical mastery of physical theater techniques, and their support of the ensemble. In future iterations of the project, I would aim to frame the work through extra-curricular or curriculum-adjacent workshops in order to remove the assessment concern.

37 The full report on the outcome of this investigation is now available to the public: https://www.nicholsschool.org/uploaded/Nichols_Public_Report.pdf?151515864083 3.

${ }^{38}$ Measure (Still) (Nichols Prompt), 18.

${ }^{39}$ Measure (Still) (Nichols Prompt), 18.

${ }^{40}$ Measure (Still) (Nichols Prompt), 21.

${ }^{41}$ see Christina Luckyj, A Moving Rhetoricke: Gender and Silence in Early Modern England (Manchester: MUP, 2002).

${ }^{42}$ Measure (Still) (Nichols Prompt), 21

${ }^{43}$ Measure (Still) (ad-lib by Brian Tank, 2017).

${ }^{44}$ Sharanya, "M4M Chorus" in Measure (Still) for Measure (unpublished: Nichols Prompt Script, 2017), 22.

45 Arthur L. Little, Jr., "What's Shakespeare to Him or He to Shakespeare?" (paper presented at the annual meeting of the Shakespeare Association of America, Atlanta, Georgia, April 6-8, 2017). Available as a podcast at: http://www.youtube.com/watch?v=4f8_sOAucWw. 